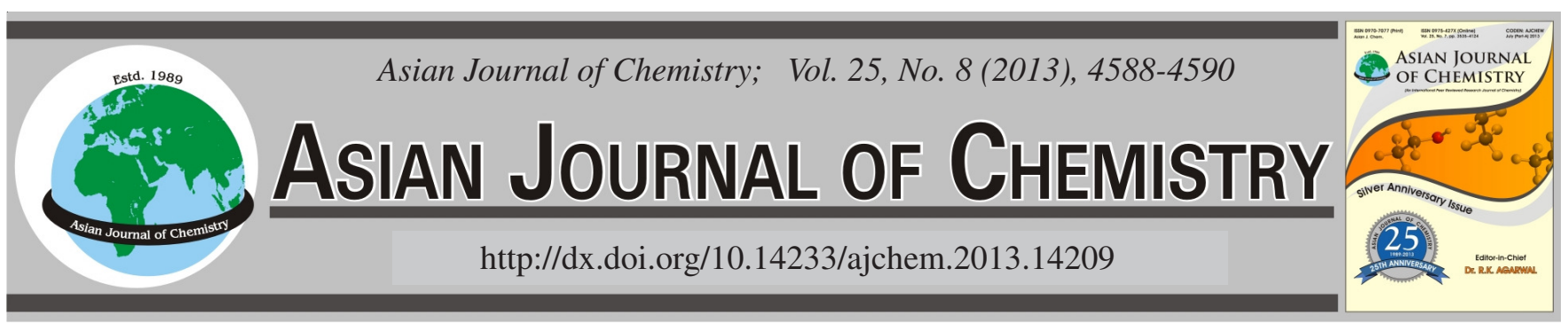

\title{
Microwave Assisted Solvent-Free One Pot Biginelli Synthesis of Dihydropyrimidinone Compounds on Melamine-Formaldehyde as a Solid Support
}



${ }^{1}$ Department of Chemistry, Firoozabad Branch, Islamic Azad University, P.O. Box 74715-117, Firoozabad, Iran

${ }^{2}$ Faculty of Science, Ahvaz Branch, Islamic Azad University, Ahvaz, Iran

*Corresponding author: E-mail: rezaieramin@yahoo.com

(Received: 18 June 2012;

Accepted: 18 February 2013)

AJC-13018

\begin{abstract}
An effective one-pot synthesis of dihydropyrimidinonoes using Melamine-formaldehyde resin supported $\mathrm{H}^{+}(\mathrm{MFRH})$ as an inexpensive and readily available reagent through Biginelli condensation reaction of aldehyde, 1,3-dicarbonyl compounds and (thio)urea in conventional and under microwave irradiation conditions is described. Excellent yields, short reaction times for formation of the products and simple work-up are attractive features of this green protocol.
\end{abstract}

Key Words: Biginelli reaction, Dihydropyrimidinones, Melamine-formaldehyde resin, One-pot, Solvent-free.

\section{INTRODUCTION}

The main benefits of performing reactions under microwave irradiation conditions are the significant rate enhancements and the higher product yields that can frequently be observed. These features have recently attracted interest from the drug discovery and medicinal chemistry communities, for which reaction speed is of great importance ${ }^{1,2}$. The combination of microwave and combinatorial chemistry applications therefore seems a logical consequence of the increased speed and effectiveness offered by using microwave irradiation instead of conventional methods.

In recent years, 3,4-dihydropyrimidin-2-(1H)-ones (DHPMs) and their derivatives have attracted considerable interest because of their therapeutic and pharmacological properties $^{3}$. They have emerged as integral backbones of several channel blockers, antihypertensive agents, $\alpha-1$ a antagonists and neuropeptide Y (NPY) antagonists ${ }^{4}$. Moreover several alkaloids containing the 3,4-dihydropyrimidin2-(1H)-one unit have been isolated from marine sources, which also exhibit interesting biological properties ${ }^{5}$. The scope of this pharmacophore has been further increased by the identification of the 4-(3-hydroxyphenyl)-2-thione derivative called monastrol $^{6}$, as a novel cell-permeable lead compound for the development of new anticancer drugs bearing the dihydropyrimidinone core. Thus the development of facile and environmentally friendly synthetic methods towards dihydropyrimidinones constitutes an active area of investigation in organic synthesis.
The synthesis of this important heterocyclic nucleus reported by Biginelli in 1893, involved a one pot condensation of ethyl acetoacetate, benzaldehyde and urea under strong acidic conditions. However, one serious drawback of the Biginelli reaction is low yields in the case of substituted aromatic and aliphatic aldehydes ${ }^{7}$. This has led to the development of multistep strategies resulting in marginally improved yields ${ }^{8}$. However, the multistep methods lack the simplicity of the one-pot, one-step procedure. Consequently, the Biginelli reaction for the synthesis of 3,4-dihydropyrimidin-2-(1H)-ones has attracted renewed attention and many improved procedures have been reported. In recent years several methods for the synthesis of 3,4-dihydropyrimidin-2-(1H)-ones have been developed to improve and modify this reaction by means of microwave irradiation ${ }^{9}$, ultrasound irradiation ${ }^{10}$, ionic liquids ${ }^{11}$, Lewis and protic acid promoters such as lanthanide triflate, ${ }^{12}$ $\mathrm{H}_{3} \mathrm{BO}_{3},{ }^{13} \mathrm{VCl}_{3},{ }^{14} \mathrm{~V}\left(\mathrm{HSO}_{4}\right)_{3},{ }^{15} \mathrm{Sr}(\mathrm{OTf})_{2},{ }^{16} \mathrm{PPh}_{3},{ }^{17}$ indium(III) halides ${ }^{18}, \mathrm{KAl}\left(\mathrm{SO}_{4}\right)_{2} \cdot 12 \mathrm{H}_{2} \mathrm{O}$ supported on silica, ${ }^{19}$ silicasulfuric acid, ${ }^{20} \mathrm{Mn}(\mathrm{OAc})_{3} \cdot 2 \mathrm{H}_{2} \mathrm{O},{ }^{21} \mathrm{Y}\left(\mathrm{NO}_{3}\right)_{3} \cdot 6 \mathrm{H}_{2} \mathrm{O},{ }^{22} \mathrm{In}(\mathrm{OTf})_{3},{ }^{23} \mathrm{TaBr}_{5},{ }^{24}$ $\mathrm{Ce}\left(\mathrm{NO}_{3}\right)_{3} \cdot 6 \mathrm{H}_{2} \mathrm{O},{ }^{25}$ silica chloride, ${ }^{26} \mathrm{HCOOH},{ }^{27} 1,3$-dichloro5,5 -dimethylhydantion ${ }^{28}$, etc. However, many of these methods involve expensive reagents, long reaction times, strongly acidic conditions and stoichiometric amount of catalysts and difficult to handle especially on a large scale. Therefore, to avoid these limitations, the introduction of a milder and more efficiently methods accompanied with higher yields are needed.

In connection with our previous work on melamine-formaldehyde resin supported $\mathrm{H}^{+}$(MFRH) as a catalyst, ${ }^{29 \mathrm{a}, \mathrm{b}}$ we wish to report the results obtained from a study of the preparation 
TABLE-1

MFRH-CATALYZED ONE-POT SYNTHESIS OF 3,4-DIHYDROPYRIMIDIN-2(1H)-ONES/THIONES

\begin{tabular}{|c|c|c|c|c|c|c|c|c|c|c|}
\hline \multirow{2}{*}{ Entry } & \multirow{2}{*}{$\mathrm{R} 1$} & \multirow{2}{*}{$\mathrm{R} 2$} & \multirow{2}{*}{ R3 } & \multirow{2}{*}{$\mathrm{X}$} & \multicolumn{2}{|c|}{ Method $\mathrm{A}^{\mathrm{a}}$} & \multicolumn{2}{|c|}{ Method B } & \multicolumn{2}{|c|}{ m.p. $\left({ }^{\circ} \mathrm{C}\right)$} \\
\hline & & & & & Time (min) & Yield $(\%)^{\mathrm{c}}$ & Time (s) & Yield $(\%)^{c}$ & Found & Reported [7-26] \\
\hline 1 & $\mathrm{Me}$ & $\mathrm{OEt}$ & $\mathrm{H}$ & $\mathrm{O}$ & 15 & 90 & 90 & 92 & $200-202$ & $201-203$ \\
\hline 2 & $\mathrm{Me}$ & $\mathrm{OEt}$ & $p-\mathrm{OCH}_{3}$ & $\mathrm{O}$ & 20 & 85 & 120 & 88 & 199-201 & $202-204$ \\
\hline 3 & $\mathrm{Me}$ & $\mathrm{OEt}$ & $p-\mathrm{CH}_{3}$ & $\mathrm{O}$ & 15 & 90 & 90 & 85 & 212-214 & $216-217$ \\
\hline 4 & $\mathrm{Me}$ & $\mathrm{OEt}$ & $p-\mathrm{Cl}$ & $\mathrm{O}$ & 15 & 80 & 120 & 90 & $208-210$ & $212-214$ \\
\hline 5 & $\mathrm{Me}$ & $\mathrm{OEt}$ & $p-\mathrm{NO}_{2}$ & $\mathrm{O}$ & 20 & 78 & 180 & 86 & 205-207 & $207-210$ \\
\hline 6 & $\mathrm{Me}$ & $\mathrm{OEt}$ & $p-\mathrm{OH}$ & $\mathrm{O}$ & 15 & 90 & 120 & 90 & $230-232$ & $231-233$ \\
\hline 7 & $\mathrm{Me}$ & $\mathrm{OEt}$ & $\mathrm{C}_{6} \mathrm{H}_{5} \mathrm{CH}=\mathrm{CH}_{2}$ & $\mathrm{O}$ & 20 & 78 & 120 & 70 & $235-237$ & $234-236$ \\
\hline 8 & $\mathrm{Me}$ & $\mathrm{OEt}$ & $m-\mathrm{NO}_{2}$ & $\mathrm{O}$ & 20 & 82 & 120 & 85 & $221-223$ & $226-228$ \\
\hline 9 & $\mathrm{Me}$ & $\mathrm{OEt}$ & $o-\mathrm{Cl}$ & $\mathrm{O}$ & 15 & 77 & 120 & 80 & $213-215$ & $216-218$ \\
\hline 10 & $\mathrm{Me}$ & $\mathrm{OEt}$ & $o-\mathrm{CH}_{3}$ & $\mathrm{O}$ & 15 & 85 & 120 & 88 & 204-206 & $208-210$ \\
\hline 11 & $\mathrm{Me}$ & OEt & $\mathrm{H}$ & $\mathrm{S}$ & 15 & 88 & 120 & 90 & 204-206 & $205-207$ \\
\hline 12 & $\mathrm{Me}$ & $\mathrm{OEt}$ & $p-\mathrm{OCH}_{3}$ & $\mathrm{~S}$ & 15 & 90 & 120 & 90 & $138-140$ & $140-142$ \\
\hline 13 & $\mathrm{Me}$ & $\mathrm{OEt}$ & $m-\mathrm{OH}$ & $\mathrm{S}$ & 20 & 80 & 120 & 85 & 183-185 & $184-186$ \\
\hline 14 & $\mathrm{Me}$ & $\mathrm{Me}$ & $\mathrm{H}$ & $\mathrm{O}$ & 25 & 75 & 180 & 80 & $228-230$ & $233-236$ \\
\hline 15 & $\mathrm{Me}$ & $\mathrm{Me}$ & $p-\mathrm{OCH}_{3}$ & $\mathrm{O}$ & 20 & 80 & 180 & 82 & $175-177$ & $178-180$ \\
\hline 16 & $\mathrm{Me}$ & $\mathrm{Ph}$ & $\mathrm{H}$ & $\mathrm{O}$ & 25 & 78 & 180 & 80 & $198-200$ & 203-204 \\
\hline 17 & $\mathrm{Me}$ & $\mathrm{Ph}$ & $\mathrm{H}$ & S & 25 & 70 & 180 & 70 & $228-230$ & $229-231$ \\
\hline 18 & $\mathrm{Ph}$ & $\mathrm{OEt}$ & $\mathrm{H}$ & $\mathrm{O}$ & 25 & 70 & 180 & 77 & $154-156$ & $157-159$ \\
\hline 19 & $\mathrm{Me}$ & $\mathrm{OMe}$ & $\mathrm{H}$ & $\mathrm{O}$ & 15 & 85 & 120 & 90 & 202-204 & $208-210$ \\
\hline 20 & $\mathrm{Me}$ & $\mathrm{OMe}$ & $p-\mathrm{NO}_{2}$ & $\mathrm{O}$ & 20 & 75 & 90 & 80 & 233-235 & $235-237$ \\
\hline
\end{tabular}

${ }^{\mathrm{a}}$ Reactants were heated using microwave irradiation; ${ }^{\mathrm{b}}$ Reactants were heated using conventional heating; ${ }^{\mathrm{c}}$ Isolated yields

of 3,4-dihydropyrimidin-2-(1H)-ones with melamine-formaldehyde resin supported $\mathrm{H}^{+}(\mathrm{MFRH})$ as a thermal and chemical stable resin, very inexpensive and easily available catalyst, under solvent-free conditions in conventional and microwave irradiation conditions

\section{EXPERIMENTAL}

All chemicals and analytical grade solvents were purchased from Merck or Fluka chemical company. Melting points were determined using a Mettler FP51 instrument. ${ }^{1} \mathrm{H}$ NMR and ${ }^{13} \mathrm{C}$ NMR spectra were recorded on a Bruker AVANCE DRX 300 spectrometer. Experiments were carried out in closed vessels of a multimode Microsynth Milstone laboratory $450 \mathrm{~W}$ west pointe microwave operating at $3.67 \mathrm{GHz}$. All experiments had good reproducibility by repeating the experiments in the same conditions. The reaction was monitored by TLC using pre-coated plates (Merck).melamine-formaldehyde resin supported $\mathrm{H}^{+}$ (MFRH) was prepared according to the below procedure.

Preparation of melamine-formaldehyde resin supported $\mathbf{H}^{+}$(MFRH): $\mathrm{HCl}$ (3.0 g, as a $36.5 \%$ aq solution) was added to a suspension of melamine-formaldehyde resin $(5 \mathrm{~g})$ in $^{2} t_{2} \mathrm{O}$ $(70.0 \mathrm{~mL})$. The mixture was concentrated and the residue was heated at $100{ }^{\circ} \mathrm{C}$ for $72 \mathrm{~h}$ under vacuum to furnish MFRH as a free flowing powder.

\section{Preparation of dihydropyrimidinone compounds}

Conventional method $(\operatorname{method} \mathbf{A})$ : A mixture of aromatic aldehyde ( $1 \mathrm{mmol})$, the $\beta$-dicarbonyl compound ( $1 \mathrm{mmol})$, urea or thiourea $(1.5 \mathrm{mmol})$ and MFRH $(0.05 \mathrm{~g}$, equal to 0.6 $\mathrm{mmol} \mathrm{H}^{+}$) was magnetically stirred in a round-bottomed flask at $80{ }^{\circ} \mathrm{C}$ for the appropriate time according to Table-1. The progress of the reaction was monitored by TLC, upon completion of the reaction; the mixture was cooled to room temperature. Reaction mixture was washed with cold water to remove excess urea or thiourea and then filtered. The remaining solid material was washed with hot ethyl acetate. The filtrate was concentrated and the solid product was recrystallized from ethanol to give the pure product (Scheme-I).

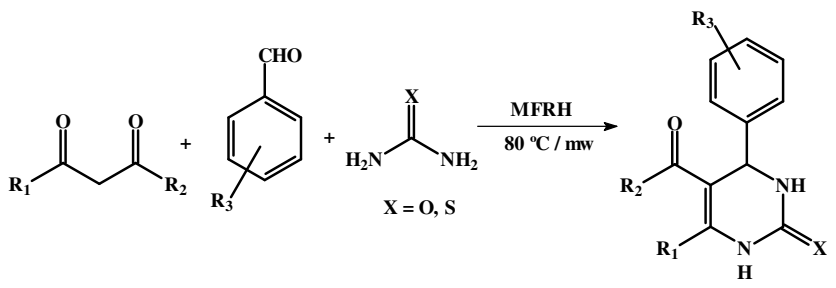

Scheme-I: Solvent-free one pot synthesis of dihydropyrimidone compounds on the melamine-formaldehyde as a solid support

Microwave method (method B): A mixture of aromatic aldehyde ( $1 \mathrm{mmol})$, the $\beta$-dicarbonyl compound ( $1 \mathrm{mmol}$ ), urea or thiourea $(1.5 \mathrm{mmol})$ and MFRH $(0.05 \mathrm{~g}$, equal to 0.6 $\mathrm{mmol} \mathrm{H}^{+}$) in a beaker was exposed to microwave irradiation for the appropriate time according to Table-1. The progress of the reaction was monitored by TLC. Upon completion of the reaction, reaction mixture was washed with cold water to remove excess urea or thiourea and then filtered. The remaining solid material was washed with hot ethyl acetate. The filtrate was concentrated and the solid product was recrystallized from ethanol to give the pure product (Scheme-I).

All the products are characterized by comparing their IR, ${ }^{1} \mathrm{H} \mathrm{NMR},{ }^{13} \mathrm{C} \mathrm{NMR}, \mathrm{MS}$ and melting points with those reported in literature ${ }^{7-26}$.

Spectral data for selected product: Compound 5: IR $\left(\mathrm{KBr}, \mathrm{v}_{\max }, \mathrm{cm}^{-1}\right): 3215,1731,1707,1641 ;{ }^{1} \mathrm{H}$ NMR (DMSO$\left.d_{6}\right): \delta_{\mathrm{H}} 1.07\left(3 \mathrm{H}, \mathrm{t},{ }^{3} J 6.8 \mathrm{~Hz}, \mathrm{CH}_{3}\right), 2.26\left(3 \mathrm{H}, \mathrm{s}, \mathrm{CH}_{3}\right), 3.97$ $\left(2 \mathrm{H}, \mathrm{q},{ }^{3} \mathrm{~J} 5.4 \mathrm{~Hz}, \mathrm{OCH}_{2}\right), 5.27(1 \mathrm{H}, \mathrm{s}, \mathrm{CH}), 7.50\left(2 \mathrm{H}, \mathrm{d},{ }^{3} \mathrm{~J} 7.3\right.$ $\mathrm{Hz}$, arom.), 7.87 (1H, s, NH), 8.20 (2H, d, ${ }^{3} J 7.2 \mathrm{~Hz}$, arom), $9.33(1 \mathrm{H}, \mathrm{s}, \mathrm{NH}) ;{ }^{13} \mathrm{C} \mathrm{NMR}: \delta_{\mathrm{C}} 14.5,18.3,54.2,59.8,98.7$, 124.2, 128.1, 147.2, 149.8, 152.2, 152.5, 165.5; $\mathrm{MS}(\mathrm{m} / \mathrm{z}, \%)$ $305\left(\mathrm{M}^{+}, 25\right), 276\left(\mathrm{M}^{+}-\mathrm{C}_{2} \mathrm{H}_{5}, 92\right), 260\left(\mathrm{M}^{+}-\mathrm{C}_{2} \mathrm{H}_{5} \mathrm{CO}_{2}, 20\right)$, 183 (100). 


\section{RESULTS AND DISCUSSION}

This method not only preserved the simplicity of Biginelli's one-pot condensation but also remarkably improved the yields $(>70 \%)$ of dihydropyrimidinones in shorter reaction times (15-25 $\mathrm{min}$ ) as against the longer reaction times required for other catalysts after the addition of a low catalyst concentration. The procedure gives the products in good yields and avoids problems associated with solvent use (cost, handling, safety and pollution). Decreased reaction times were also realized because of the increased reactivity of the reactant in the solid state. In order to improve the yields, we started to study the three-component Biginelli condensation catalyzed with MFRH by examining the conditions required for the reaction involving ethyl acetoacetate, benzaldehyde and urea to afford the DHPM1 [R1 = Me, R2 = OEt, R3 = H, X=O, S (Table-1)].

Reactions at different conditions and various molar ratios of substrates in the presence of MFRH, were revealed that the best result was achieved by carry out the reaction (with 1:1:1.5 mol ratio of ethyl acetoacetate, benzaldehyde and urea) in the presence of. $0.6 \mathrm{~mol}$ of $\mathrm{H}^{+}$at $80{ }^{\circ} \mathrm{C}$ for 15 min under solventfree conditions (Table-1, entry 1). Under similar condition, aromatic aldehydes bearing electron-withdrawing and -donating groups afforded the corresponding DHPMs in high yields and purity (Table-1). In order to study the generality of this protocol, acetylacetone, benzoylacetone, ethylbenzoyl-acetate and methyl acetoacetate were used in place of ethyl acetoacetate (Table-1, entries 14-20) to furnish corresponding DHPMs. Thiourea was used with similar success to provide the corresponding3,4dihydropyrimidin-2-(1H)-thiones which are also of interest with regard to their biological activities. For example monastrol, was obtained in a $80 \%$ yield (Table-1, entry 13). The catalyst has been successfully reused for second and third time and obtained DHPM in almost similar yield (entry 1, $87 \%$ and 83 $\%$, respectively). In absence of MFRH, the reaction remains incomplete and impurities were increasedupon further exposure to microwave for an extended period (method B).

MFRH is a versatile solid support based on 1,3,5triazine core. In our research on tarnsformation processe ${ }^{29 a, b}$ it has been found that MFRH is a solid support that is very well suited for microwave synthesis. As it is an ionic and magnetically retrievable material, it carries the benefit of an efficient conversion of electromagnetic energy into heat according to the dielectric heating mechanism (Table-1). This compound behaves as an efficient microwave adsorbent, this resulting in turn in a very rapid and homogeneous heating. Consequently, they display very strong specific microwave effects, with significant improvements in temperature homogeneity and heating rates, enabling faster reactions and less degradation of final products when compared to classical heating (Table$1)$.

In view of environmentally friendly procedure, the recovery and reuse of this catalyst is quite preferable. MFRH was easily separated from the reaction medium by filtering and regenerated by washing with water and ethyl acetate, followed by drying at room temperature. Among the various catalysts used for preparation of DHPMs ${ }^{9-28}$, MFRH was found more preferable catalyst because of its suitable reactivity, availability and low cost.
In conclusion, we have described use of melamine-formaldehyde resin supported $\mathrm{H}^{+}$(MFRH) as an efficient catalyst for the synthesis of 3,4-dihydropyrimidin-2-(1H)-ones and thione analogs by multicomponent Biginelli reactions under solvent-free conditions, using both conventional heating and microwave irradiation. The advantages of this procedure over earlier reported processes include its simplicity, fast and clean reactions, high yield and the absence of organic solvent. It was found that the reactions under microwave irradiation were proceeded more rapidly and in higher yields. Further work is in progress to extend the catalytic activity of melamine-formaldehyde resin supported $\mathrm{H}^{+}$to other organic transformations.

\section{ACKNOWLEDGEMENTS}

The authors gratefully thank the Chemical Research Center of Islamic Azad University, Firoozabad Branch for their valuable help of this work.

\section{REFERENCES}

1. M. Larhed and A. Hallberg, Drug Discov. Today, 6, 406 (2001).

2. J.L. Krstenansky and I. Cotterill, Curr. Opin. Drug Discov. Dev., 4, 454 (2000)

3. C.O. Kappe, Tetrahedron, 49, 6937 (1993).

4. G.C. Rovnyak, S.D. Kimball, B. Beyer, G. Cucinotta, J.D. DiMarco, J.Z. Gougoutas, A. Hedberg, M.F. Malley, J.P. McCarthy, R. Zhang and S.J. Moreland, Med. Chem., 38, 119 (1995).

5. L.E. Overman, M.H. Rabinowitz and P.A. Renhowe, J.Am. Chem. Soc., 117, 2657 (1995).

6. T.U. Mayer, T.M. Kapoor, S.J. Haggarty, R.W. King, S.L. Schreiber and T.J. Mitchison, Science, 286, 971 (1999).

7. P. Biginelli, Gazz. Chim. Ital., 23, 360 (1893).

8. B.C. O'Reilly and K.S. Atwal, Heterocycles, 26, 1185 (1987).

9. B.K. Banik, A.T. Reddy, A. Datta and C. Mukhopadhyay, Tetrahedron Lett., 48, 7392 (2007).

10. J.T. Li, J.F. Han, J.H. Yang and T.S. Li, Ultrason. Sonochem., 10, 119 (2003).

11. J.J. Peng and Y.Q. Deng, Tetrahedron Lett., 42, 5917 (2001).

12. Y. Ma, C. Qian, L. Wang and M. Yang, J. Org. Chem., 65, 3864 (2000).

13. S.J. Tu, F. Fang, C.B. Miao, H. Jiang, Y.J. Feng, D.Q. Shi and X.S. Wang, Tetrahedron Lett., 44, 6153 (2003).

14. G. Sabitha, G.S.K.K. Reddy, K.B. Reddy and J.S. Yadav, Tetrahedron Lett., 44, 6497 (2003).

15. F. Shirini, A. Yahyazadeh, M. Abedini and D.I. Langroodi, Bull. Korean Chem. Soc., 31, 1715 (2010).

16. W.K. Su, J.J. Li, Z.G. Zheng and H.C. Shen, Tetrahedron Lett., 46, 6037 (2005).

17. A. Debache, M. Amimour, A. Belfaitah, S. Rhouati and B.A. Carboni, Tetrahedron Lett., 49, 6119 (2008).

18. N.Y. Fu, Y.F. Yuan, M.L. Pang, J.T. Wang and C. Peppe, Organomet. Chem., 672, 52 (2003).

19. J. Azizian, A.A. Mohammadi, A.R. Karimi and M.R. Mohammadizadeh, Appl. Catal. A, 300, 85 (2006).

20. P. Salehi, M. Dabiri, M.A. Zolfigol and M.A.B. Fard, Tetrahedron Lett., 44, 2889 (2003).

21. K.A. Kumar, M. Kasthuraiah, C.S. Reddy and C.D. Reddy, Tetrahedron Lett., 42, 7873 (2001).

22. N.S. Nandurkar, M.J. Bhanushali, M.D. Bhor and B.M. Bhanage, J. Mol. Catal. A, 271, 14 (2007)

23. R. Ghosh, S. Maiti and A. Chakraborty, J. Mol. Catal. A, 217, 47 (2004).

24. N. Ahmed and J.E.V. Lier, Tetrahedron Lett., 48, 5407 (2007).

25. M. Adib, K. Ghanbary, M. Mostofi and M.R. Ganjali, Molecules, 11, 649 (2006)

26. H.N. Karade, M. Sathe and M.P. Kaushik, Molecules, 12, 1341 (2007).

27. J. Cheng and D.Y. Qi, Chin. Chem. Lett., 18, 647 (2007).

28. S.F. Hojati, M. Gholizadeh, M. Haghdoust and F. Shafiezadeh, Bull. Korean Chem. Soc., 31, 3238 (2010).

29. (a) R. Rezaei, M.K. Mohammadi and N. Rastin, Chin. J. Chem., 28, 993 (2010); (b). R. Rezaei and M. Karami, Chin. Chem. Lett., 22, 815 (2011). 